This is a postprint version of the following article: Quiroz-Padilla, MF; Guillazo-Blanch G.; Sánchez, MY; Domínguez Sánchez, MA; Gómez, RM (2017). Effects of excitotoxic lesion with inhaled anesthetics on nervous system cells of rodents. Current Pharmaceutical Design, vol. 23. ISSN: 1381-6128. DOI: 10.2174/1381612823666170817125015

\title{
EFFECTS OF EXCITOTOXIC LESION WITH INHALED ANESTHETICS ON NERVOUS SYSTEM CELLS OF RODENTS
}

Quiroz-Padilla Maria F $\mathrm{PhD}^{1}$., Guillazo-Blanch Gemma $\mathrm{PhD}^{2}$., Sanchez Magdy

$\mathrm{MSc}^{3,4}$., Dominguez Maria A MSc ${ }^{5}$, Gomez Rosa M., PhD. ${ }^{4}$

\section{Affiliations:}

${ }^{1}$ Laboratorio de Bases Biológicas del Comportamiento. Facultad de Psicología. Universidad de la Sabana, Bogotá, Colombia.

${ }^{2}$ Departamento de Psicobiología y Metodología de las Ciencias de la Salud. Instituto de Neurociencias. Universidad Autónoma de Barcelona.

${ }^{3}$ Facultad de Enfermería y Rehabilitación. Programa de Fisioterapia. Universidad de la Sabana, Bogotá, Colombia.

${ }^{4}$ Fundación de Neuroregeneración en Colombia. Grupo de investigación NeuroRec Bogotá, Colombia.

${ }^{5}$ Facultad de Enfermería y Rehabilitación. Programa de Fisioterapia.Grupo de investigación movimiento corporal humano. Universidad de la Sabana, Bogotá, Colombia.

\section{*Correspondence should be addressed to: Maria Fernanda Quiroz Padilla PhD}

Facultad de Psicología, Universidad de la Sabana.

Campus Universitario del Puente del Común, Km 7

Autopista Norte de Bogotá, D.C.

Colombia

Call Center: 8615555 / 8616666 Ext. 28307

E-mail: mariaqp@unisabana.edu.co

None of the authors have any financial interests in this research. 


\title{
EFFECTS OF EXCITOTOXIC LESION WITH INHALED ANESTHETICS ON NERVOUS SYSTEM CELLS OF RODENTS
}

\begin{abstract}
Summary
Different anesthesia methods can variably influence excitotoxic lesion effects on the brain. The main purpose of this review is to identify potential differences in the toxicity to nervous system cells of two common inhalation anesthesia methods, isoflurane and sevoflurane, used in combination with an excitotoxic lesion procedure in rodents. The use of bioassays in animal models has provided the opportunity to examine the role of specific molecules and cellular interactions that underlie important aspects of neurotoxic effects relating to calcium homeostasis and apoptosis activation. Processes induced by MNDA antagonist drugs involve translocation of Bax protein to mitochondrial membranes, allowing extra-mitochondrial leakage of cytochrome c, followed by sequence of changes that ending in activation of CASP-3. The literature demonstrates that the use of these anesthetics in excitotoxic surgery increases neuroinflammation activity facilitating the effects of apoptosis and necrosis on nervous system cells, depending on the concentration and exposure duration of the anesthetic. These inflammatory responses are possibly mediated by high numbers of microglia and astrocytes and high levels of proinflammatory cytokines and caspase activation.
\end{abstract}

Keywords: astrocyte, caspases, cytokines, excitotoxic lesion, isoflurane, sevoflurane. 


\section{Introduction}

Studies in animal models, especially in rodents, during recent years have identified possible toxic effects on the brain of using general inhaled anesthesia [1,2]. The majority of researches have shown the susceptibility of brain development processes in the neonatal rat to N-metil-Daspartate receptor (NMDAR) and Gamma-Aminobutyric Acid ${ }_{A}\left(\mathrm{GABA}_{\mathrm{A}}\right)$ receptor antagonist, which can result in massive apoptosis or necrosis [3-9].

Excitotoxic lesions in rodents result in two principal types of cell death, primary and secondary (Fig. 1, Extrinsic and Intrinsic pathway). In the first type, excitotoxicity is direct and occurs when there is an overactivation of glutamate receptors. Without energy to maintain the ionic gradients, the resting potential of neurons collapses. The resulting depolarization produces a massive release of the excitatory neurotransmitter glutamate and a lack of energy which is difficult to recapture by specific transporters $[10,11]$. Some of the most used chemical substances for primary excitotoxic lesions are N-metil-D-aspartate (NMDA) and kainic acid (KA), ibotenic, and quinolinic or 2, 3-Pyridine-Dicarboxylic (QUIN) acid [12-15]. In the second type of cell death, the lesion is indirect and happens either when metabolic processes produce an accumulation of oxygen radicals by oxidative stress or when changes induced by mitochondrial impairment promote inflammation of cells in the nervous system [16-19]. This reaction causes overactivation of microglia producing cytokines such as tumor necrosis factor- alpha (TNF- $\alpha$ ), interleukin-6 (IL-6), and interleukin-1ßeta (IL-1 $\beta$ ) [20, 21]. Another possible explanation may be caspase activation in the cell, producing chromatin condensation and deoxyribonucleic acid (DNA) fragmentation. These can be key features of apoptotic cells, which are ultimately eliminated by phagocytes [22-25].

The main inhalant anesthetics used today in experimental processes with rodents are isoflurane and sevoflurane. These volatile anesthetics can have neurodevelopmental effects depending on concentration and exposure duration, affected cell plasticity, and neurocognitive performance [19, 26-28]. When exposure to these anesthetics has been in the period between postnatal day (PD) 7 and PD14 it has been associated with apoptosis processes, especially in hippocampal stem cells and dentate gyrus (DG) granule neurons [19, 27, 29, 30]. The immature rodent brain is most vulnerable to anesthesia-induced neurotoxicity, whether administered by inhalation or intraperitoneal (i.p) injection, in the intrauterine period and up until 2 to 3 weeks after birth [19, 31, 32]. However, the toxicity effects of inhaled anesthetics are not well understood, especially in the nerve cells of juvenile and adult rodents. 
This review has as its main aim briefly to discuss the effects of the use of the inhaled anesthetics, isoflurane and sevoflurane, in combination with excitotoxic lesion procedures in rodents. First, we describe the molecular effects of substances most commonly used in the models of excitotoxic injuries in rodents. Second, we analyze the studies of inhalant anesthetics and their role in the protection against or the induction of cytotoxicity in the cells of the nervous system.

\section{Molecular mechanisms of the substances used in the models of excitotoxic lesions in rodents}

The choice and use of the excitotoxins in the lesion model play a role important in the experimental studies with rodents, especially in stroke, traumatic brain injury, spinal cord injury and neurodegenerative diseases of the central nervous system. We describe the main molecular effects of NMDA, KA and QUIN in the nerve cells.

\subsection{NMDA and NMDAR}

Molecular mechanisms underlying preconditioning (the brain has the ability to protect itself against ischemia when it stimulated by some anesthetics and other drugs), the are not completely elucidated, with the possible implication on different occasions of NMDAR, nitric oxide synthase, cytokines, and mitochondrial oxidative stress. Bioenergetic modulation and suppression of the innate immune system are two of the elements that have pivotal roles in such processes [33-36]. NMDA and other glutamatergic agents in particular may act as chemical preconditioning agents in hippocampal slices [37], in cultured cells [38] and in in vivo models of excitotoxicity [39]. Additionally, subtoxic doses of NMDA (e.g., $75 \mathrm{mg} / \mathrm{kg}$, i.p.) yield preconditioning against chemically-induced seizure $[39,40]$ or traumatic brain injury in vivo [41]. This concept was extended to in vivo models of QUIN induced seizures [33, 39, 42]. Other research confirms that NMDA preconditioning does not induce neuronal death per se, and its neuroprotective mechanisms remain to be fully elucidated [43] .

Recent studies show that NMDAR dysfunction contributes to the neurotoxicity that underlies many neurodegenerative disorders [44-48]. Examples of NMDAR that have been used to model pathogenesis of neurocognitive disorders associated with human immunodeficiency virus (HIV) involves a combination of factors [49], evidence suggests that the HIV protein trans activator of transcription (Tat) plays a prominent role by altering the activity of NMDARs [49-52] and impairing cognitive function [53-55]. Tat potentiated NMDAR function via lipoproteinreceptor-related protein-dependent activation of Src kinase. Also, NMDAR function adapted 
after activation of the nitric oxide synthases (NOS), soluble guanylate cyclase (sGC), and protein kinase $\mathrm{G}$ (PKG) pathways [50]. Additional research determined that a ras homolog gene family member A (RhoA) / associated kinase (ROCK) dependent remodeling of the actin cytoskeleton was an obligatory step in NMDAR adaptation. This function may be a neuroprotective mechanism to prevent excessive NMDAR-mediated $\mathrm{Ca}^{2+}$ influx [56]. On the other hand, activation and inhibition of RhoA profoundly affected neuronal morphology, consistent with previous reports $[57,58]$ that neurons expressing dominant negative (DN)-RhoA exhibited increased dendritic branching, whereas cells expressing CA-RhoA displayed simplified dendritic structures with minimal branching and no noticeable dendritic spines [56].

It has been shown that ROCK is the primary downstream target of RhoA and is a serine/threonine kinase that modifies the cytoskeleton to regulate cell migration and proliferation $[59,60]$, and that activation of ROCK in neurons induces rundown of NMDAR currents via an actin-dependent mechanism [61]. Additional research found that inhibition of ROCK prevented adaptation of NMDAR function following Tat-induced potentiation. These data indicate that Tat-induced activation of ROCK reduces NMDAR function. Abnormal activation of ROCK is also observed in many models of neuronal disorders including Alzheimer's disease, spinal cord injury, neuropathic pain, and excitotoxicity lesion [62].

Moreover, it has been shown that Tat affects the cytoskeleton: it depolymerizes actin in endothelial cells [63] and produces a loss of F-actin puncta in hippocampal neurons in vitro [64]. The data indicate that Tat activates a RhoA/ROCK pathway leading to remodeling of the actin cytoskeleton resulting in reduced NMDA-evoked responses [50]. The same research also indicates that the observed effects of Tat on NMDAR function may result from both direct effects on neurons and indirect effects on glia. Indeed, Tat promotes the release of glutamate [65], inflammatory cytokines [66], chemokines [67], and reactive oxygen species [68], from glia and neurons [50]. These substances all influence NMDAR function.

However, studies in which DN constructs were expressed selectively in neurons determined that potentiation of NMDAR function required activation of neuronal Src kinase, while adaptation required activation of a neuronal NO signaling pathway [50]. ROCK is a valuable drug target with neuroprotective and neuroregenerative potential. The ROCK inhibitor, fasudil, is a welltolerated vasodilator that has been used clinically [69], and is neuroprotective in models of Alzheimer's disease [70], amyotrophic lateral sclerosis [71], and Parkinson's disease [72]. 
Is a glutamate analog that stimulates excitatory neurotransmitter release and induces ischemialike neuronal degeneration. It has been used to define mechanisms involved in neurodegeneration and neuroprotection, and is a powerful neurotoxic agent [73] that stimulates excitatory neurotransmitter release [74]. Systemic KA injection induces neuronal degeneration in certain brain areas, including the piriform cortex, amygdaloid complex, hippocampus, and septum [74-78]. The nature of neuronal degeneration caused by systemic KA injection resembles some forms of ischemia [79]. The degree of KA-induced neuronal injury is influenced by temperature, anesthesia, and anticonvulsant drugs $[80,81]$.

In general, the intranasal (IN) anesthesia has been shown to provoke acute central cytotoxicity and neuronal damage, reflecting the penetration of the anesthetic into the brain [82]. KA may be used to trigger electrographic status epileptics (ES) and the associated sequel of proinflammatory changes [83]. The results in one study, had shown IN KA induced ES on brain inflammation, and microglia- astrocytic cell activation, and hippocampal neurodegeneration. [84]. Moreover, the same research found phenotypic microglial activation and astrogliosis, along with transcriptional modifications of inflammatory genes. Microgliosis was observed as early as 24 hours after IN KA-induced ES; the results showed that microglial M1 and M2 genes were dysregulated. M1 corresponds to a pro-inflammatory status, correlating to or facilitating neuronal damage. In contrast, the anti-inflammatory M2 phenotype may be beneficial following pathological events in the brain [84, 85]. Typical pro-inflammatory brain changes were observed in this model, supporting disease pathophysiology. A possibility for tailoring this model to drug testing or to study mechanisms of disease is offered [86, 87].

KAR subunits play roles in the brain that are quite distinct from those played by other members of the ionotropic glutamate receptor (iGluR) family, despite structural and functional commonalities. While $\alpha$-amino-3-hydroxy-5-methyl-4-isoxazolepropionic acid receptors (AMPARs) and NMDARs mediate most basal excitatory synaptic transmission due to their position in postsynaptic densities, KARs seem to have more diverse functions that rely on a diversity of subcellular localization and signaling mechanisms. They thus play a unique role in regulating the activity of neural circuits and are distributed throughout the nervous system [88].

Interestingly, KARs are not involved in short-term plasticity at Schaffer collateral synapses onto CA1 pyramidal cells [89], pointing to the target-specific localization of presynaptic KARs in given afferents, in contrast to the moderate facilitation observed for other interneurons [90]. Presynaptic calcium-permeable KARs is thought to be involved in the short-term facilitation of 
glutamate release based on the use of the calcium-permeable receptor antagonist 1- napthyl acetyl spermine (NASPM) [90]. Excitatory synapses, in cells of the striatum orients, also show pronounced facilitation, which is attenuated with NS102, a selective glutamate receptor ionotropic kainate 2 (GluK2) antagonist [91].

In summary, although CA3 pyramidal cells appear to show the highest expression of KAR subunits (GluK2, GluK4 and GluK5), in agreement with the high density of H3-kainate binding sites, expression of KARs is far from being restricted to CA3 pyramidal cells [58]. KAR subunits are also expressed in CA1 pyramidal cells (GluK2 and GluK5) and in granule cells of the DG (GluK2, GluK3, GluK4 and GluK5) as well as in interneurons of the striatum orients and striatum radiatum (GluK1, GluK2 and in part GluK3). There is no evidence thus far for expression of KAR subunits in glial cells under control conditions [88].

\subsection{QUIN}

QUIN is a component of a major metabolic pathway of tryptophan degradation and can modulate some local events in the central nervous system [92]. However, under pathological conditions, it is capable of inducing a potent neurotoxic pattern by different mechanisms [93, 94]. Under normal conditions, QUIN is produced as a downstream transient metabolite of tryptophan involved in adenine dinucleotide (NAD+) synthesis, since the kynurenine pathway typically catalyzes L-tryptophan into NAD+. In mammals, the majority of tryptophan comes from dietary intake, and is metabolized by the kynurenine pathway [93]. This metabolite is normally present in nano-molar concentrations in human and rat brains [95] and in nano- to micro-molar concentrations in cerebrospinal fluid [96].

However, under inflammatory conditions, the kynurenine pathway is stimulated by cytokines, particularly by interferon- $\gamma$ (IFN- $\gamma$ ). In macrophages the exposure of corticostriatal structures to sub-micro-molar concentrations of QUIN has been shown to induce neuronal cell death through an excitotoxic mechanism [94], suggesting that this toxin can trigger multiple toxic cascades even at low concentrations. Moreover, excitotoxicity induced by QUIN has also been related to its ability to increase reactive oxygen species (ROS) / reactive nitrogen species (RNS) formation and further oxidative damage [92]. Other studies report that the intrastriatal infusion of QUIN into rodents stimulates lipid peroxidation in this region within 2 hours post lesion [97], and these findings have been correlated with increased extracellular levels of hydroxyl radical in the striatum [98]. As a result of these and other findings, there is a hypothesis that at least a fraction of the oxidative and cell damage induced by QUIN could correspond with components that are independent of NMDAR overactivation [98, 99]. QUIN not only induces damage to neurons, 
but also to glial cells. This discovery presents a new perspective on the toxic properties of this agent, and highlights the importance of designing therapeutic alternatives for neurological disorders involving glial cells [92].

A recent study has shown that all currently known NMDAR subunits (particularly NR1 and NR2A) are expressed in primary astrocytes, albeit at different levels [100]. Calcium influx studies have shown that QUIN activates astrocytic NMDARs, which stimulate $\mathrm{Ca} 2+$ influx into the cell. This results in dysfunction and death of astrocytes. The NMDAR ion channel blockers MK801 and memantine attenuate QUIN-mediated cell excitotoxicity. This suggests that the mechanism of QUIN gliotoxicity is at least partially mediated by excessive stimulation of NMDARs and the mechanism of action of QUIN on astrocytes is likely to be mediated by NMDARs. [101].

The molecular effects of receptors such as NMDA, KA and QUIN in the nerve cells have been studied predominantly in the ionotropic glutamate receptor of NMDA, because it allow that extracellular calcium moves down a great concentration gradient into cell and also trigger the release of calcium from intracellular cytoplasmic compartment. Through potent neurotoxic pattern by different mechanisms QUIN activates astrocytic NMDARs, which stimulate calcium influx into the cell, as well as QUIN-mediated cell excitotoxicity. Moreover, KA will help in brain inflammation, and microglia- astrocytic cell activation, and hippocampal neurodegeneration.

\section{Role of the use of inhaled anesthetics in protection against or induction of cytotoxicity in cells of the nervous system}

Isoflurane and sevoflurane are halogenated ethers used for general inhalational anesthesia. These volatile anesthetics reduce pain sensitivity and relax muscles. The differing effects of both anesthetics on the immature and mature nervous system have been investigated in recent years using in vitro Table 1 and in vivo murine models Table 2 . The dates indicate that isoflurane and sevoflurane can inhibit NMDA receptor responses; these results suggest that both anesthetics might also be able to reduce or increase cytotoxic effects produced by excessive NMDA receptor stimulation, especially in the developing nervou s system [102-106]

In the nervous system of the developing rat, the deleterious effects of volatile anesthetics have demonstrated their greatest potential for harm between PD 0 - PD 14 [29, 30, 107-109] Studies have determined the presence of apoptosis in the developing nervous system, as measured by 
expression of activated caspase-3 (CASP-3) and increases induced by the expression in proteins of cleaved CASP-3, for both isoflurane and sevoflurane [29, 30, 108, 109].

This increased expression has been observed in the neocortex [109, 110], thalamus [109], hippocampal dentate gyrus, CA1 and CA3 [29, 30, 109, 111]. among other brain regions [108], as much as 24 hours after the last inhalation [30].

It has also been observed that isoflurane increased other neurodegenerative biomarkers such as S100B in the blood, poly-(ADP-ribose) polymerase, protein levels of glyceraldehyde-3phosphate dehydrogenase, beta-site amyloid beta-precursor protein-cleaving enzyme, and the cell cycle regulatory proteins on CDK4 and cyclin D1 [108]. Other markers of degeneration have been found, including necrosis (as measured by calpain activation, and the fodrin breakdown product FBDP), DNA strand breaks (TUNEL), autophagy (LC3), and independent (AIF) apoptosis [29, 30]

Cytotoxic effects of inhaled anesthetic in neonatal rats are further associated with reduced expression of neural nitric oxide synthases (nNOS), which may participate in neuronal apoptosis [111], and induction of apoptosis regulator (Bax) activation without significant cell death. This suggests that Bax activation may lead to destabilized mitochondria, in turn promoting cell vulnerability to insult, and eventual cell death [103, 112].

Moreover, maternal intrauterine exposure to anesthetic has also been shown to have harmful effects on the developing nervous system, with both isoflurane and sevoflurane inducing morphological and molecular changes [103, 113]. It has been identified that exposure to isoflurane in embryogenic cells triggers such changes as crista mitochondriales impairment, vacuolar degeneration, dilation of rough endoplasmic reticulum in irregular caryomorphism, and the appearance of apoptotic bodies in the cytoplasm [103]. Sevoflurane (1 minimal alveolar concentration (MAC), $2 \%$ for $12 \mathrm{~h}$ ) induced cytotoxicity in primary rat cortical neurons, which was also associated with a high and fast elevation of peak Changes of calcium concentration in cytosolic space $(\mathrm{Ca} 2+\mathrm{c})$ [113]. Isoflurane, but not desflurane, induces opening of mitochondrial permeability transition pore (mPTP), increase in levels of reactive oxygen species (ROS), reduction in levels of mitochondrial membrane potential and adenosine-5'-triphosphate (ATP), activation of CASP-3, in hippocampus neurons mouse and mice [114].

On the other hand, the exposure of gestating but not pregestation rats to sevoflurane induced extensive apoptotic neurodegeneration in the hippocampus of offspring at PD 0 , PD 7, and PD 14, accompanied by altered expression of CASP-3, GAP-43, nNOS, NMDAR1, and 
NMDAR2A, along with NMDAR2B upregulation of PKC $\alpha$ and p-JNK and downregulation of p-ERK and FOS protein levels [115].

In the nervous system of adult rats, isoflurane exposure for 1 MAC for 12 hours induced cytoxicity increased IP3R gene expression, and inhibition of IP3R activity did not completely block isoflurane-induced upregulation of IP3R mRNA expression, which was also associated with greater and faster elevation of peak $(\mathrm{Ca} 2+)$. Sevoflurane and desflurane at equivalent exposure to isoflurane did not induce similar cytotoxicity or elevation of peak $(\mathrm{Ca} 2+)[104,113]$

In conclusion isoflurane and sevoflurane induce cytotoxicity in the nervous system, which has significant adverse effects on neonatal and postnatal stage. In the adult effects nervous system result in increased vulnerability to cell damage. The variety of mechanisms explaining this toxicity is related to overstimulation of NMDA, CASP-3 increases (induced expression levels of protein cleaved CASP-3) and neuronal apoptosis by reduction of nNOS expression and activation Bax induction. These findings occur during exposure to even MAC for 12 hours.

\section{The use of inhaled anesthetics in protecting or inducing cytotoxicity in glial cells}

The effects on glial cells, the inhaled anesthetic isoflurane especially inhibit the induction of lipopolysaccharide (LPS) increases proinflammatory cytokines IL $-1 \beta$ and affects participation HPA axis hypothalamic-pituitary-adrenal stress response in specifically on microglia [110]. Prolonged exposure to high concentrations of isoflurane induces significant cell damage, inhibits cell proliferation and promoted glial cell fate [113].

With respect to sevoflurane anesthetic, recent studies on the toxic effect of compound A (a product of degradation of sevoflurane produced by its interaction with absorbent carbon dioxide) it has been identified that cell degeneration progressed over time resulting in the loss of all viable cells. Even short exposures resulted in the massive cell death indicating that the compound $\mathrm{A}$ is a potent toxin for glial cells in vitro. A plausible mechanism for this toxicity involves the depletion of intracellular glutathione resulting in oxidative stress.

In in vitro experiments, volatile anesthetics cause cell death in a population of glial cells induced by oxidative stress because these anesthetics act on iron serving as a promoter for protection against the toxicity and thus reduce indirect oxidative stress intracellular caused by this challenge [103]. 
In brief, the effects of inhaled anesthetics on the population of glial cells showed cell damage possibly by alterations in the cell membrane; channels of affected joints of the membrane, in the induction of lipopolysaccharide and alteration of the input and output mechanisms of substances such as glutathione. As indicated there is a greater inflammatory response and generation mechanisms of oxidative stress are responsible for the cell death and decreased the rate of proliferation of glial cells. Some of these mechanisms in vitro studies demonstrated the potential protection of inhaled anesthetics.

\section{Conclusion}

In conclusion, toxicities in chemical injury of the central nervous system can be an inflammatory response mediated by high densities of microglia and astrocytes, high levels of proinflammatory cytokines, and caspase activation. Studies with rodents are essential to understanding the effect of the use of inhaled anesthetics with excitotoxic lesions in different developmental stages, including newborns, juveniles and adults. Understanding the mechanisms of regulation of cell death during development can potentially provide tools to promote neuroprotection and eventually achieve the repair of the nervous system in pathological conditions. Also certain substances, such as QUIN, not only induce damage to neurons, but also to glial cells. These properties of the agents used in excitotoxicity should be investigated with further research ranging from experimental model in vivo and in vitro, to therapeutic substitutes for neurological disorders involving glial cells.

\section{Acknowledgments}

The authors thank Dr. Gordon Ingram for helpful comments. 


\section{REFERENCES}

[1] Larsen M, Haugstad TS, Berg-Johnsen J, Langmoen IA. Effect of isoflurane on release and uptake of gamma-aminobutyric acid from rat cortical synaptosomes. Br J Anaesth, 1998; 80: 634-8.

[2] Larsen M, Langmoen IA. The effect of volatile anaesthetics on synaptic release and uptake of glutamate. Toxicol Lett, 1998; 100-101: 59-64.

[3] Ikonomidou C, Bosch F, Miksa M, Bittigau P, Vöckler J, Dikranian K, Tenkova TI, Stefovska V, Turski L, Olney JW. Blockade of NMDA receptors and apoptotic neurodegeneration in the developing brain. Science, 1999; 283: 70-4.

[4] Jevtovic-Todorovic V, Hartman RE, Izumi Y, Benshoff ND, Dikranian K, Zorumski CF, Olney JW, Wozniak DF. Early exposure to common anesthetic agents causes widespread neurodegeneration in the developing rat brain and persistent learning deficits. J Neurosci, 2003; 23: 876-82.

[5] Yon JH, Daniel-Johnson J, Carter LB, Jevtovic-Todorovic V. Anesthesia induces neuronal cell death in the developing rat brain via the intrinsic and extrinsic apoptotic pathways. Neuroscience, 2005; 135: 815-27.

[6] Fredriksson A, Pontén E, Gordh T, Eriksson P. Neonatal exposure to a combination of N-methyl-D-aspartate and gamma-aminobutyric acid type A receptor anesthetic agents potentiates apoptotic neurodegeneration and persistent behavioral deficits. Anesthesiology, 2007; 107: 427-36.

[7] Wang X, Zhao B, Li X. Dexmedetomidine attenuates isoflurane-induced cognitive impairment through antioxidant, anti-inflammatory and anti-apoptosis in aging rat. Int J Clin Exp Med, 2015; 8: 17281-8.

[8] Li G, Xue Q, Luo Y, Hu X, Yu B. S6 inhibition contributes to isoflurane neurotoxicity in the developing brain. Toxicol Lett, 2015; 233: 102-13.

[9] Sitdikova G, Zakharov A, Janackova S, Gerasimova E, Lebedeva J, Inacio AR, Zaynutdinova D, Minlebaev M, Holmes GL, Khazipov R. Isoflurane suppresses early cortical activity. Ann Clin Transl Neurol, 2014; 1: 15-26.

[10] Choi DW. Ionic dependence of glutamate neurotoxicity. J Neurosci, 1987; 7: 369-79.

[11] Lau A, Tymianski M. Glutamate receptors, neurotoxicity and neurodegeneration. Pflugers Arch, 2010; 460: 525-42.

[12] Quiroz-Padilla MF, Guillazo-Blanch G, Vale-Martinez A, Torras-Garcia M, Marti-Nicolovius M. Effects of parafascicular excitotoxic lesions on two-way active avoidance and odor-discrimination. Neurobiology of Learning and Memory, 2007; 88: 198-207.

[13] Lanciego JL, Rodríguez-Oroz MC, Blesa FJ, Alvarez-Erviti L, Guridi J, Barroso-Chinea P, Smith Y, Obeso JA. Lesion of the centromedian thalamic nucleus in MPTP-treated monkeys. Mov Disord, 2008; 23: 708-15.

[14] Wolf R, Matzke K, Paelchen K, Dobrowolny H, Bogerts B, Schwegler H. Reduction of Prepulse Inhibition (PPI) after neonatal excitotoxic lesion of the ventral thalamus in pubertal and adult rats. Pharmacopsychiatry, 2010; 43: 99109.

[15] Ghorayeb I, Fernagut PO, Hervier L, Labattu B, Bioulac B, Tison F. A 'single toxin-double lesion' rat model of striatonigral degeneration by intrastriatal 1methyl-4-phenylpyridinium ion injection: a motor behavioural analysis. Neuroscience, 2002; 115: 533-46.

[16] Beal MF. Excitotoxicity and nitric oxide in Parkinson's disease pathogenesis. Ann Neurol, 1998; 44: S110-4. 
[17] Beal MF. Mitochondrial dysfunction in neurodegenerative diseases. Biochim Biophys Acta, 1998; 1366: 211-23.

[18] Cheng Y, Mitchell-Flack MJ, Wang A, Levy RJ. Carbon monoxide modulates cytochrome oxidase activity and oxidative stress in the developing murine brain during isoflurane exposure. Free Radic Biol Med, 2015; 86: 191-9.

[19] Lu Y, Huang Y, Jiang J, Hu R, Yang Y, Jiang H, Yan J. Neuronal apoptosis may not contribute to the long-term cognitive dysfunction induced by a brief exposure to $2 \%$ sevoflurane in developing rats. Biomed Pharmacother, 2016: 322-8.

[20] van Gool WA, van de Beek D, Eikelenboom P. Systemic infection and delirium: when cytokines and acetylcholine collide. Lancet, 2010; 375: 773-5.

[21] Shen X, Dong Y, Xu Z, Wang H, Miao C, Soriano SG, Sun D, Baxter MG, Zhang Y, Xie Z. Selective anesthesia-induced neuroinflammation in developing mouse brain and cognitive impairment. Anesthesiology, 2013; 118: 502-15.

[22] Martinvalet D, Zhu P, Lieberman J. Granzyme A induces caspase-independent mitochondrial damage, a required first step for apoptosis. Immunity, 2005; 22: 355-70.

[23] Cohen GM. Caspases: the executioners of apoptosis. Biochem J, 1997; 326 ( Pt 1): 1-16.

[24] Rai NK, Tripathi K, Sharma D, Shukla VK. Apoptosis: a basic physiologic process in wound healing. Int J Low Extrem Wounds, 2005; 4: 138-44.

[25] Elmore S. Apoptosis: a review of programmed cell death. Toxicol Pathol, 2007; 35: 495-516.

[26] Yang Y, Song S, Min H, Chen X, Gao Q. STAT3 degradation mediated by calcineurin involved in the neurotoxicity of isoflurane. Neuroreport, 2016; 27: 124-30.

[27] Xiao H, Liu B, Chen Y, Zhang J. Learning, memory and synaptic plasticity in hippocampus in rats exposed to sevoflurane. Int J Dev Neurosci, 2016; 48: 3849.

[28] Li C, Wang Q, Li L, Liu Y, Diao H. Arachidonic acid attenuates learning and memory dysfunction induced by repeated isoflurane anesthesia in rats. Int J Clin Exp Med, 2015; 8: 12365-73.

[29] Fang F, Xue Z, Cang J. Sevoflurane exposure in 7-day-old rats affects neurogenesis, neurodegeneration and neurocognitive function. Neuroscience bulletin, 2012; 28: 499-508.

[30] Zhu C, Gao J, Karlsson N, Li Q, Zhang Y, Huang Z, Li H, Kuhn HG, Blomgren $\mathrm{K}$. Isoflurane anesthesia induced persistent, progressive memory impairment, caused a loss of neural stem cells, and reduced neurogenesis in young, but not adult, rodents. Journal of Cerebral Blood Flow \& Metabolism, 2010; 30: 10171030.

[31] Fredriksson A, Archer T, Alm H, Gordh T, Eriksson P. Neurofunctional deficits and potentiated apoptosis by neonatal NMDA antagonist administration. Behav Brain Res, 2004; 153: 367-76.

[32] Liu F, Paule MG, Ali S, Wang C. Ketamine-induced neurotoxicity and changes in gene expression in the developing rat brain. Curr Neuropharmacol, 2011; 9: 256-61.

[33] Vandresen-Filho S, de Araujo Herculano B, Franco JL, Boeck CR, Dafre AL, Tasca CI. Evaluation of glutathione metabolism in NMDA preconditioning against quinolinic acid-induced seizures in mice cerebral cortex and hippocampus. Brain Res, 2007; 1184: 38-45. 
[34] Shpargel KB, Jalabi W, Jin Y, Dadabayev A, Penn MS, Trapp BD. Preconditioning paradigms and pathways in the brain. Cleve Clin J Med, 2008; 75 Suppl 2: S77-82.

[35] Severino PC, Muller Gdo A, Vandresen-Filho S, Tasca CI. Cell signaling in NMDA preconditioning and neuroprotection in convulsions induced by quinolinic acid. Life Sci, 2011; 89: 570-6.

[36] Boeck CR, Carbonera LS, Milioli ME, Constantino LC, Garcez ML, Rezin GT, Scaini G, Streck EL. Mitochondrial respiratory chain and creatine kinase activities following trauma brain injury in brain of mice preconditioned with $\mathrm{N}$ methyl-D-aspartate. Mol Cell Biochem, 2013; 384: 129-37.

[37] Schurr A, Payne RS, Tseng MT, Gozal E, Gozal D. Excitotoxic preconditioning elicited by both glutamate and hypoxia and abolished by lactate transport inhibition in rat hippocampal slices. Neurosci Lett, 2001; 307: 151-4.

[38] Xu GP, Dave KR, Vivero R, Schmidt-Kastner R, Sick TJ, Perez-Pinzon MA. Improvement in neuronal survival after ischemic preconditioning in hippocampal slice cultures. Brain Res, 2002; 952: 153-8.

[39] Boeck CR, Ganzella M, Lottermann A, Vendite D. NMDA preconditioning protects against seizures and hippocampal neurotoxicity induced by quinolinic acid in mice. Epilepsia, 2004; 45: 745-50.

[40] Ogita K, Okuda H, Yamamoto Y, Nishiyama N, Yoneda Y. In vivo neuroprotective role of NMDA receptors against kainate-induced excitotoxicity in murine hippocampal pyramidal neurons. J Neurochem, 2003; 85: 1336-46.

[41] Costa T, Constantino LC, Mendonca BP, Pereira JG, Herculano B, Tasca CI, Boeck CR. N-methyl-D-aspartate preconditioning improves short-term motor deficits outcome after mild traumatic brain injury in mice. J Neurosci Res, 2010; 88: $1329-37$.

[42] de Araujo Herculano B, Vandresen-Filho S, Martins WC, Boeck CR, Tasca CI. NMDA preconditioning protects against quinolinic acid-induced seizures via PKA, PI3K and MAPK/ERK signaling pathways. Behav Brain Res, 2011; 219: 92-7.

[43] Costantino HR, Illum L, Brandt G, Johnson PH, Quay SC. Intranasal delivery: physicochemical and therapeutic aspects. Int J Pharm, 2007; 337: 1-24.

[44] Young AB, Greenamyre JT, Hollingsworth Z, Albin R, D'Amato C, Shoulson I, Penney JB. NMDA receptor losses in putamen from patients with Huntington's disease. Science, 1988; 241: 981-3.

[45] Danysz W, Parsons CG. The NMDA receptor antagonist memantine as a symptomatological and neuroprotective treatment for Alzheimer's disease: preclinical evidence. Int J Geriatr Psychiatry, 2003; 18: S23-32.

[46] Hallett PJ, Standaert DG. Rationale for and use of NMDA receptor antagonists in Parkinson's disease. Pharmacol Ther, 2004; 102: 155-74.

[47] Rossi S, Studer V, Moscatelli A, Motta C, Coghe G, Fenu G, Caillier S, Buttari F, Mori F, Barbieri F, Castelli M, De Chiara V, Monteleone F, Mancino R, Bernardi G, Baranzini SE, Marrosu MG, Oksenberg JR, Centonze D. Opposite roles of NMDA receptors in relapsing and primary progressive multiple sclerosis. PLoS One, 2013; 8: e67357.

[48] Spalloni A, Nutini M, Longone P. Role of the N-methyl-d-aspartate receptors complex in amyotrophic lateral sclerosis. Biochim Biophys Acta, 2013; 1832: 312-22.

[49] Chandra T, Maier W, König HG, Hirzel K, Kögel D, Schüler T, Chandra A, Demirhan I, Laube B. Molecular interactions of the type 1 human 
immunodeficiency virus transregulatory protein Tat with $\mathrm{N}$-methyl-d-aspartate receptor subunits. Neuroscience, 2005; 134: 145-53.

[50] Krogh KA, Wydeven N, Wickman K, Thayer SA. HIV-1 protein Tat produces biphasic changes in NMDA-evoked increases in intracellular $\mathrm{Ca} 2+$ concentration via activation of Src kinase and nitric oxide signaling pathways. J Neurochem, 2014; 130: 642-56.

[51] Song L, Nath A, Geiger JD, Moore A, Hochman S. Human immunodeficiency virus type 1 Tat protein directly activates neuronal N-methyl-D-aspartate receptors at an allosteric zinc-sensitive site. J Neurovirol, 2003; 9: 399-403.

[52] Haughey NJ, Nath A, Mattson MP, Slevin JT, Geiger JD. HIV-1 Tat through phosphorylation of NMDA receptors potentiates glutamate excitotoxicity. J Neurochem, 2001; 78: 457-67.

[53] Fitting S, Xu R, Bull C, Buch SK, El-Hage N, Nath A, Knapp PE, Hauser KF. Interactive comorbidity between opioid drug abuse and HIV-1 Tat: chronic exposure augments spine loss and sublethal dendritic pathology in striatal neurons. Am J Pathol, 2010; 177: 1397-410.

[54] Carey AN, Sypek EI, Singh HD, Kaufman MJ, McLaughlin JP. Expression of HIV-Tat protein is associated with learning and memory deficits in the mouse. Behav Brain Res, 2012; 229: 48-56.

[55] Bachani M, Sacktor N, McArthur JC, Nath A, Rumbaugh J. Detection of anti-tat antibodies in CSF of individuals with HIV-associated neurocognitive disorders. J Neurovirol, 2013; 19: 82-8.

[56] Krogh KA, Lyddon E, Thayer SA. HIV-1 Tat activates a RhoA signaling pathway to reduce NMDA-evoked calcium responses in hippocampal neurons via an actin-dependent mechanism. J Neurochem, 2015; 132: 354-66.

[57] Da Silva JS, Medina M, Zuliani C, Di Nardo A, Witke W, Dotti CG. RhoA/ROCK regulation of neuritogenesis via profilin IIa-mediated control of actin stability. J Cell Biol, 2003; 162: 1267-79.

[58] Chen H, Firestein BL. RhoA regulates dendrite branching in hippocampal neurons by decreasing cypin protein levels. J Neurosci, 2007; 27: 8378-86.

[59] Matsui T, Amano M, Yamamoto T, Chihara K, Nakafuku M, Ito M, Nakano T, Okawa K, Iwamatsu A, Kaibuchi K. Rho-associated kinase, a novel serine/threonine kinase, as a putative target for small GTP binding protein Rho. EMBO J, 1996; 15: 2208-16.

[60] Amano M, Nakayama M, Kaibuchi K. Rho-kinase/ROCK: A key regulator of the cytoskeleton and cell polarity. Cytoskeleton (Hoboken), 2010; 67: 545-54.

[61] Beazely MA, Weerapura M, MacDonald JF. Abelson tyrosine kinase links PDGFbeta receptor activation to cytoskeletal regulation of NMDA receptors in CA1 hippocampal neurons. Mol Brain, 2008; 1: 20.

[62] Mueller BK, Mack H, Teusch N. Rho kinase, a promising drug target for neurological disorders. Nat Rev Drug Discov, 2005; 4: 387-98.

[63] Wu RF, Gu Y, Xu YC, Mitola S, Bussolino F, Terada LS. Human immunodeficiency virus type 1 Tat regulates endothelial cell actin cytoskeletal dynamics through PAK1 activation and oxidant production. J Virol, 2004; 78: 779-89.

[64] Bertrand SJ, Mactutus CF, Aksenova MV, Espensen-Sturges TD, Booze RM. Synaptodendritic recovery following HIV Tat exposure: neurorestoration by phytoestrogens. J Neurochem, 2014; 128: 140-51.

[65] Eugenin EA, King JE, Nath A, Calderon TM, Zukin RS, Bennett MV, Berman JW. HIV-tat induces formation of an LRP-PSD-95- NMDAR-nNOS complex 
that promotes apoptosis in neurons and astrocytes. Proc Natl Acad Sci U S A, 2007; 104: 3438-43.

[66] Chen P, Mayne M, Power C, Nath A. The Tat protein of HIV-1 induces tumor necrosis factor-alpha production. Implications for HIV-1-associated neurological diseases. J Biol Chem, 1997; 272: 22385-8.

[67] Conant K, Garzino-Demo A, Nath A, McArthur JC, Halliday W, Power C, Gallo RC, Major EO. Induction of monocyte chemoattractant protein-1 in HIV-1 Tatstimulated astrocytes and elevation in AIDS dementia. Proc Natl Acad Sci U S A, 1998; 95: 3117-21.

[68] Kruman, II, Nath A, Mattson MP. HIV-1 protein Tat induces apoptosis of hippocampal neurons by a mechanism involving caspase activation, calcium overload, and oxidative stress. Exp Neurol, 1998; 154: 276-88.

[69] Shibuya M, Suzuki Y, Sugita K, Saito I, Sasaki T, Takakura K, Nagata I, Kikuchi H, Takemae T, Hidaka H, et al. Effect of AT877 on cerebral vasospasm after aneurysmal subarachnoid hemorrhage. Results of a prospective placebocontrolled double-blind trial. J Neurosurg, 1992; 76: 571-7.

[70] Song Y, Chen X, Wang LY, Gao W, Zhu MJ. Rho kinase inhibitor fasudil protects against beta-amyloid-induced hippocampal neurodegeneration in rats. CNS Neurosci Ther, 2013; 19: 603-10.

[71] Takata M, Tanaka H, Kimura M, Nagahara Y, Tanaka K, Kawasaki K, Seto M, Tsuruma K, Shimazawa M, Hara H. Fasudil, a rho kinase inhibitor, limits motor neuron loss in experimental models of amyotrophic lateral sclerosis. $\mathrm{Br} \mathrm{J}$ Pharmacol, 2013; 170: 341-51.

[72] Tonges L, Frank T, Tatenhorst L, Saal KA, Koch JC, Szego EM, Bahr M, Weishaupt JH, Lingor P. Inhibition of rho kinase enhances survival of dopaminergic neurons and attenuates axonal loss in a mouse model of Parkinson's disease. Brain, 2012; 135: 3355-70.

[73] Ferkany JW, Zaczek R, Coyle JT. Kainic acid stimulates excitatory amino acid neurotransmitter release at presynaptic receptors. Nature, 1982; 298: 757-9.

[74] Schwob JE, Fuller T, Price JL, Olney JW. Widespread patterns of neuronal damage following systemic or intracerebral injections of kainic acid: a histological study. Neuroscience, 1980; 5: 991-1014.

[75] Nadler JV, Cuthbertson GJ. Kainic acid neurotoxicity toward hippocampal formation: dependence on specific excitatory pathways. Brain Res, 1980; 195: 47-56.

[76] Nadler JV, Evenson DA, Cuthbertson GJ. Comparative toxicity of kainic acid and other acidic amino acids toward rat hippocampal neurons. Neuroscience, 1981; 6: 2505-17.

[77] Heggli DE, Aamodt A, Malthe-Sorenssen D. Kainic acid neurotoxicity; effect of systemic injection on neurotransmitter markers in different brain regions. Brain Res, 1981; 230: 253-62.

[78] Lothman EW, Collins RC. Kainic acid induced limbic seizures: metabolic, behavioral, electroencephalographic and neuropathological correlates. Brain Res, 1981; 218: 299-318.

[79] Coyle JT. Kainic acid: insights into excitatory mechanisms causing selective neuronal degeneration. Ciba Found Symp, 1987; 126: 186-203.

[80] Nabeka H, Uematsu K, Takechi H, Shimokawa T, Yamamiya K, Li C, Doihara T, Saito S, Kobayashi N, Matsuda S. Prosaposin overexpression following kainic acid-induced neurotoxicity. PLoS One, 2014; 9: e110534. 
[81] Nabeka H, Shimokawa T, Doihara T, Saito S, Wakisaka H, Hamada F, Kobayashi N, Matsuda S. A prosaposin-derived Peptide alleviates kainic Acidinduced brain injury. PLoS One, 2015; 10: e0126856.

[82] Chen Z, Ljunggren HG, Bogdanovic N, Nennesmo I, Winblad B, Zhu J. Excitotoxic neurodegeneration induced by intranasal administration of kainic acid in C57BL/6 mice. Brain Res, 2002; 931: 135-45.

[83] Legido A, Katsetos CD. Experimental studies in epilepsy: immunologic and inflammatory mechanisms. Semin Pediatr Neurol, 2014; 21: 197-206.

[84] Sabilallah M, Fontanaud P, Linck N, Boussadia B, Peyroutou R, Lasgouzes T, Rassendren FA, Marchi N, Hirbec HE. Evidence for Status Epilepticus and ProInflammatory Changes after Intranasal Kainic Acid Administration in Mice. PLoS One, 2016; 11: e0150793.

[85] Marchi N, Lerner-Natoli M. Cerebrovascular remodeling and epilepsy. Neuroscientist, 2013; 19: 304-12.

[86] Donnelly DJ, Gensel JC, Ankeny DP, van Rooijen N, Popovich PG. An efficient and reproducible method for quantifying macrophages in different experimental models of central nervous system pathology. J Neurosci Methods, 2009; 181: 36-44.

[87] O'Callaghan JP, Jensen KF, Miller DB. Quantitative aspects of drug and toxicant-induced astrogliosis. Neurochem Int, 1995; 26: 115-24.

[88] Carta M, Fievre S, Gorlewicz A, Mulle C. Kainate receptors in the hippocampus. Eur J Neurosci, 2014; 39: 1835-44.

[89] Sun HY, Dobrunz LE. Presynaptic kainate receptor activation is a novel mechanism for target cell-specific short-term facilitation at Schaffer collateral synapses. J Neurosci, 2006; 26: 10796-807.

[90] Sun HY, Bartley AF, Dobrunz LE. Calcium-permeable presynaptic kainate receptors involved in excitatory short-term facilitation onto somatostatin interneurons during natural stimulus patterns. J Neurophysiol, 2009; 101: 104355.

[91] Sylwestrak EL, Ghosh A. Elfn1 regulates target-specific release probability at CA1-interneuron synapses. Science, 2012; 338: 536-40.

[92] Perez-De La Cruz V, Carrillo-Mora P, Santamaria A. Quinolinic Acid, an endogenous molecule combining excitotoxicity, oxidative stress and other toxic mechanisms. Int J Tryptophan Res, 2012; 5: 1-8.

[93] Perez-De La Cruz V, Konigsberg M, Santamaria A. Kynurenine pathway and disease: an overview. CNS Neurol Disord Drug Targets, 2007; 6: 398-410.

[94] Schwarcz R, Guidetti P, Sathyasaikumar KV, Muchowski PJ. Of mice, rats and men: Revisiting the quinolinic acid hypothesis of Huntington's disease. Prog Neurobiol, 2010; 90: 230-45.

[95] Chen Y, Meininger V, Guillemin GJ. Recent advances in the treatment of amyotrophic lateral sclerosis. Emphasis on kynurenine pathway inhibitors. Cent Nerv Syst Agents Med Chem, 2009; 9: 32-9.

[96] Schwarcz R, Pellicciari R. Manipulation of brain kynurenines: glial targets, neuronal effects, and clinical opportunities. J Pharmacol Exp Ther, 2002; 303: 110.

[97] Santamaria A, Salvatierra-Sanchez R, Vazquez-Roman B, Santiago-Lopez D, Villeda-Hernandez J, Galvan-Arzate S, Jimenez-Capdeville ME, Ali SF. Protective effects of the antioxidant selenium on quinolinic acid-induced neurotoxicity in rats: in vitro and in vivo studies. J Neurochem, 2003; 86: 47988. 
[98] Santamaria A, Jimenez-Capdeville ME, Camacho A, Rodriguez-Martinez E, Flores A, Galvan-Arzate S. In vivo hydroxyl radical formation after quinolinic acid infusion into rat corpus striatum. Neuroreport, 2001; 12: 2693-6.

[99] Behan WM, McDonald M, Darlington LG, Stone TW. Oxidative stress as a mechanism for quinolinic acid-induced hippocampal damage: protection by melatonin and deprenyl. Br J Pharmacol, 1999; 128: 1754-60.

[100] Lee MC, Ting KK, Adams S, Brew BJ, Chung R, Guillemin GJ. Characterisation of the expression of NMDA receptors in human astrocytes. PLoS One, 2010; 5: e14123.

[101] Guillemin GJ. Quinolinic acid, the inescapable neurotoxin. FEBS J, 2012; 279: 1356-65.

[102] Harada H, Kelly PJ, Cole DJ, Drummond JC, Patel PM. Isoflurane reduces Nmethyl-D-aspartate toxicity in vivo in the rat cerebral cortex. Anesth Analg, 1999; 89: 1442-7.

[103] Wang Y, Cheng Y, Liu G, Tian X, Tu X, Wang J. Chronic exposure of gestation rat to sevoflurane impairs offspring brain development. Neurological Sciences, 2012; 33: 535-544.

[104] Zhai W, Zhao J, Huo S, Chen X, Li Y, Zhang Z, Yu L, Song S, Wang Q. Mechanisms of cytotoxicity induced by the anesthetic isoflurane: the role of inositol 1, 4, 5-trisphosphate receptors. Genetics and molecular research: GMR, 2015; 14: 6929.

[105] Zheng S, Zuo Z. Isoflurane preconditioning induces neuroprotection against ischemia via activation of P38 mitogen-activated protein kinases. Mol Pharmacol, 2004; 65: 1172-80.

[106] Zheng S, Zuo Z. Isoflurane preconditioning decreases glutamate receptor overactivation-induced Purkinje neuronal injury in rat cerebellar slices. Brain Res, 2005; 1054: 143-51.

[107] Bercker S, Bert B, Bittigau P, Felderhoff-Müser U, Bührer C, Ikonomidou C, Weise M, Kaisers UX, Kerner T. Neurodegeneration in newborn rats following propofol and sevoflurane anesthesia. Neurotoxicity research, 2009; 16: 140-147.

[108] Liang G, Ward C, Peng J, Zhao Y, Huang B, Wei H. Isoflurane causes greater neurodegeneration than an equivalent exposure of sevoflurane in the developing brain of neonatal mice. The Journal of the American Society of Anesthesiologists, 2010; 112: 1325-1334.

[109] Loepke AW, Istaphanous GK, McAuliffe III JJ, Miles L, Hughes EA, McCann JC, Harlow KE, Kurth CD, Williams MT, Vorhees CV. The effects of neonatal isoflurane exposure in mice on brain cell viability, adult behavior, learning, and memory. Anesthesia \& Analgesia, 2009; 108: 90-104.

[110] Liang G, Wang Q, Li Y, Kang B, Eckenhoff MF, Eckenhoff RG, Wei H. A presenilin-1 mutation renders neurons vulnerable to isoflurane toxicity. Anesthesia \& Analgesia, 2008; 106: 492-500.

[111] Zhou X, Song F-H, He W, Yang X-Y, Zhou Z-B, Feng X, Zhou L-H. Neonatal exposure to sevoflurane causes apoptosis and reduces nNOS protein expression in rat hippocampus. Molecular medicine reports, 2012; 6: 543-546.

[112] Yan H, Xu T, Zhao H, Lee K-C, Wang H-Y, Zhang Y. Isoflurane increases neuronal cell death vulnerability by downregulating miR-214. PloS one, 2013; 8: e55276.

[113] Qiujun W, 王秋筠, Kezhong L, 李克忠, Shanglong Y, 姚尚 $\square$. Effect of inhalational anesthetics on cytotoxicity and intracellular calcium differently in 
rat pheochromocytoma cells (PC12). Journal of Huazhong University of Science and Technology [Medical Sciences], 2008; 28: 104-109.

[114] Zhang Y, Xu Z, Wang H, Dong Y, Shi HN, Culley DJ, Crosby G, Marcantonio ER, Tanzi RE, Xie Z. Anesthetics isoflurane and desflurane differently affect mitochondrial function, learning, and memory. Annals of neurology, 2012; 71: 687-698.

[115] Wang Q, Li K, Yao S, Li Z, Liu S. Different effects of isoflurane and sevoflurane on cytotoxicity. Chinese medical journal, 2008; 121: 341.

[116] Zheng H, Dong Y, Xu Z, Crosby G, Culley DJ, Zhang Y, Xie Z. Sevoflurane anesthesia in pregnant mice induces neurotoxicity in fetal and offspring mice. The Journal of the American Society of Anesthesiologists, 2013; 118: 516-526$516-526$.

[117] Wu B, Yu Z, You S, Zheng Y, Liu J, Gao Y, Lin H, Lian Q. Physiological disturbance may contribute to neurodegeneration induced by isoflurane or sevoflurane in 14 day old rats. PloS one, 2014; 9: e84622. 